\title{
REALIZING OUTDOOR INDEPENDENT LEARNING WITH A BUTTERFLY-WATCHING MOBILE LEARNING SYSTEM ${ }^{*}$
}

\author{
YUH-SHYAN CHEN \\ Department of Computer Science and Information Engineering \\ National Chung Cheng University \\ TAI-CHIEN KAO \\ Institute of Education \\ National Dong Hwa University \\ JANG-PING SHEU \\ Departmemt of Computer Science and Information Engineering \\ National Central University
}

\begin{abstract}
In this paper, we describe the development of a mobile butterfly-watching learning (BWL) system to realize outdoor independent learning for mobile learners. The mobile butterfly-watching learning system was designed in a wireless mobile ad-hoc learning environment. This is first result to provide a cognitive tool with supporting the independent learning by applying PDA with wireless communication technology to extend learning outside of the classroom. Independent learning consists of self-selection, self-determination, self-modification, and self-checking. To support independent learning, we designed useful butterfly-watching learning subsystems to offer the self-selection, self-determination, self-modification, and self-checking functionality. The study sample consisted of twenty-four five-year students who enrolled in natural science course in the Fall of 2003 in Taiwan. The study lasted fourth months (one semester). During the butterfly-watching activity, each learner arbitrarily took a distinct butterfly picture and entered it into his own PDA to acquire the butterfly knowledge anytime and anywhere through wireless communication. The potential impacts, limitations, and lessons learned from this study are discussed from both the educational and technological points of view. Mobile outside classroom learning potentially extends the scope of learning activities and with more flexibility than in traditional school curriculum. This work shows that the concept of applying PDA with wireless communication technology is a "new cognitive learning tool" to personally access, analyze, interpret, and organize their personal knowledge anytime and anywhere.
\end{abstract}

*This work was supported by Learning Technology, sponsored by the Ministry of Education, Taiwan: 92A-H-FA07-1-4 and by a grant NSC 93-2524-S-194-005 from the National Science Council of the R.O.C. 


\section{INTRODUCTION}

As educational media tend to become more mobilized, portable, and individualized, the learning form is dramatically changing. With the aid of advances in wireless communication technology (Johnson, \& Maltz, 1996; Chen, Chen, \& Huang, 2002; Chen, \& Ko, 2004), educational practices can now become embedded in our daily lives. For learning that extends beyond the school context, learners require independence as a life skill, to assist them in preparing for new situations and experiences. Tatar, Roschelle, Vahey, and Penuel (2003) illustrated the use of mobile handheld devices in school for lessons and learning.

One way of promoting knowledge as design is to use computers as cognitive tools. Cognitive tools differ from the more traditional 'instructivist' notation of computer technology in that they do not provide prescribed communication or interaction, not do they transmit bodies of knowledge (Jonassen \& Reeves, 1996). To be able to use technology as a cognitive tool, it is necessary to provide an appropriate learning context for the learners. Jonassen and Reeves (1996) have stated that learning with technology requires a constructivist learning context. Cognitive tools are unintelligent applications (Jonassen, 1996) that provide flexible, didactic supports which encourage students to make maximum use of their own intelligent and knowledge structures. This study attempts to use PDA (small-sized computer) with wireless communication technology as cognitive tools for learning inside and outside of the classroom. With cognitive tools, information is not presented in the educational material to be learned. Yildirim (2005) stated that The students use the computers as cognitive tools to access, analyze, interpret, and organize their personal knowledge. The concept of applying PDA with wireless communication technology is a "new cognitive learning tool” to access, analyze, interpret, and organize their personal knowledge anytime and anywhere.

From a constructivist perspective, the purpose of education is to cultivate independent and self-directed learners. Bruner's metaphor of scaffolding (Bruner, 1983) provides an explicit strategy to direct teaching toward this end. The method of scaffolding consists of two major processes; one is ‘support building' and another one is ‘support fading'. Cazden (1988) has used a vivid and familiar picture to make clear the concept and the pervasiveness of its exemplars. Bruner (1983), Greenfield (1984), and Cazden (1988) proposed that scaffolding can enhance comprehension, improve independent learning and application, and promote knowledge transfer. Evidence of these advantages has been found in many studies in the field of language and cognitive development (Boyle \& Peregoy, 1990; Gallimore et al., 1989; Day \& Cordon, 1993). Day and Cordon (1993) developed a method of scaffolding using five levels of support, where they faded support in a sequence of authentic practices. Using Day and Cordon's model, Kao and Lehman (1997) proposed the basic elements of scaffolded instruction which are especially relevant to integrated-media design.

However, independent learning is considered an important design issue as we begin to make use of the media capabilities of wireless communication technologies to make a difference in learning. Independent learning can assist students in acquiring the knowledge, abilities, skills, 
values, and motivation that will enable them to analyze learning situations and develop appropriate strategies for action (Kesten, 1987; Herber, \& Nelson-Herber, 1987; Tough, 1986; McDonald, \& Ingvarson, 1997; Weasmer, \& Woods, 2001; Thomas, 1993; Marsh, 1997; Houston, \& Lazenbatt, 1996; Sivan, Leung, Woon, \& Kember, 2000; Maitland, 2000; Lafferty, 1996; Martens, Valcke, \& Portier, 1997). Education needs to focus on creating opportunities and experiences necessary for students to become capable, self-reliant, and self-motivated learners. In the process, independent learners develop the values, attitudes, knowledge, and skills needed to make responsible decisions and take actions dealing with their own learning. This approach to learning encourages students to produce meaning for themselves, based on their understanding of why and how new knowledge is related to their own experiences, interests, and needs. This work mainly investigates how to design a new learning system with independent learning.

Lehner \& Nosekabel (2002) recently defined mobile learning as a "service or facility that supplies a learner with general electronic information and educational content that aids in acquisition of knowledge regardless of location and time." Sariola (2001) discusses the advantages of mobile learning, "The mobile environment integrates studies that take place on campus, at home or outside university facilities into shared and flexible learning environment.” Kynäslahti (2003) defined the word mobility from the educational point of view. He argues that the elements of mobility include convenience, expediency, and immediacy. Chang et al. (2003) proposed three essential elements of mobile learning: mobile equipments, communications technology, and user interfaces. A mobile learning system for scaffolding bird watching learning was developed by Chen, Kao, and Sheu (2003) to simulate the support provided by wild bird guides, which share the cognitive load of bird identification when a learner is engaged in outdoor bird watching activities. The findings provided evidence that the system not only promoted bird-identification abilities but also enhanced the independence of learners. Following the successful experience of scaffolding, this paper further focuses on learning situations when the support of instructors is gradually withdrawn. The proposed system intends to provide mobile aids for students to become capable, self-reliant, self-motivated, and independent learners when they are engaged in outdoor activities of exploring nature on their own. This is also the key difference between the bird watching learning system and the newly developed learning system for butterfly-watching.

To support independent learning, a mobile butterfly-watching learning (BWL) system was implemented to empower the learner to engage in independent butterfly-watching activities. In this investigation, we describe the development of the BWL system to promote outdoor independent learning for mobile learners. This is first result to provide a cognitive tool with supporting the independent learning by applying PDA with wireless communication technology to extend learning outside of the classroom. The proposed BWL system was designed for use in wireless mobile ad-hoc learning environment. The independent learning process consists of self-selection, self-determination, self-modification, and self-checking. To support independent learning, we designed butterfly-watching learning subsystems to provide the capabilities for self-selection, self-determination, self-modification, and self-checking. To provide the self-selection environment, a mobile butterfly picture-input subsystem was designed on a personal handheld device (a 
personal digit assistant, PDA). To supply the self-determination procedure, a wireless query subsystem was developed. To offer the self-modification tools, a content-based butterfly image retrieval subsystem was then designed. To support the self-checking platform, mobile journal and pre/post-test subsystems were finally designed. The study sample consisted of twenty-four five-year students who enrolled in natural science course in the Fall of 2003 in Taiwan. The study lasted fourth months (one semester). During the butterfly-watching activity, each learner arbitrarily took a distinct butterfly picture and entered it into his own PDA to acquire the butterfly knowledge anytime and anywhere through wireless communication. The potential impacts, limitations, and lessons learned from this study are discussed from both the educational and technological points of view. Mobile outside classroom learning potentially extends the scope of learning activities and with more flexibility than in traditional school curriculum. This work illustrates the evidence that the concept of applying PDA with wireless communication technology is a "new cognitive learning tool" to personally access, analyze, interpret, and organize their personal knowledge anytime and anywhere.

\section{THEORETICAL FRAMEWORK}

In this investigation, we developed a mobile butterfly-watching learning (BWL) system, which is based on mobile ad hoc networks (Chen, Kao, \& Sheu, 2003; Chen, Chen, \& Huang, 2002; Chen, \& Ko, 2004) to establish a mobile outdoor learning environment to extend learning outside of the classroom. As shown in Figure 1, three knowledge domains are considered in our BWL system; the content, learning, and technique domains are mobile butterfly watching, independent learning, and wireless communication, respectively.

From our experience with scaffolding bird-watching learning described in (Chen, Kao, \& Sheu, 2003), we believe that scaffolding may help beginners more-easily acquire knowledge if the beginner has no self-learning ability. But when a learner has fundamental knowledge and self-learning ability to overcome a problem, the teacher may relinquish control to the learner. The challenging work of this study was to investigate the independent learning model by conducting a traditional butterfly-watching activity. This was done by providing a very user-friendly interface in a mobile learning environment. As shown in Figure 2, the independent learning model (Tough, 1986) includes four learning components: self-selection, self-determination, self-modification, and self-checking. The relations among these four components can logically be represented by a system flow, or loop, as shown in Figure 2. Efforts will be made in this work is to design the BWL system with supporting the independent learning.

To achieve the self-selection and self-determination capabilities, the BWL system allows each learner to independently study and learn butterfly knowledge and information in an outdoor natural environment. In addition, the teacher possibly helps learners achieve the self-modification and self-checking capability with the aid of the BWL system. The most important spirit of education is to help learners have self-confidence, technology, and knowledge when they attempt to seek solutions. Then, learners can independently and actively participate in their own learning. 
Characteristics of the independent learning model are learning knowledge more independently and acquiring information more easily. After that, learners can extend their own learning abilities.

One interesting task and challenge of our work was to offer a butterfly image-recognition subsystem based on the content-based image-retrieval technique (Li, Chen, Shyu, \& Furht, 2002; Jhanwar, Chaudhuri, Seetharaman, \& Zavidovique, 2002; Kak, Pavolpoulo, Kak, \& Pavlopoulou, 2002; Huang, Zhou, Nakazato, Wu, \& Cohen, 2002; Guo, Jain, Ma, \& Zhang, 2001). This butterfly image-recognition subsystem can help learners arbitrarily and independently acquire useful butterfly knowledge and information without giving input data and features of an observed butterfly during the butterfly-watching learning activity. Meanwhile the learner can observe differences among butterflies with many similar features. The main contribution of the BWL system is that it provides a user-friendly system to educate learners on how to acquire self-selection, self-determination, self-modification, and self-checking abilities during the learning process. In our system, the traditional teacher role can relinquish control of decision-making to learners. In addition, the role of the wireless network technology was to immediately provide mobile learning knowledge. As to the immediate knowledge, it is possible for learners to acquire information anytime and anywhere based on new wireless technologies and mobile learning systems.

The learning flow chart of the mobile butterfly-watching activity is shown in Figure 3. In the BWL activity, the teacher has to carry a notebook as a local server. This notebook has a complete database of butterflies in Taiwan. The main function of BWL system is (1) learners can learn and identify the family, name, ecology, and behavior of a butterfly anytime and anywhere; (2) we design a mobile note system during the butterfly-watching activity to upload our notes into the teacher's machine by wireless communication; and those data with the teacher's comments were returned to each learner's handheld device again by wireless communication. Each team, consisting of two students, was given a PDA with a WiFi (IEEE 802.11b) wireless network card and a color CCD camera, or a copy of a guidebook depending on the group it belonged to. The butterfly-watching procedures for independent learning were as follows.

1. Self-selection process: The learners in the team find one of the target butterflies of interest and take a close picture of it.

2. Self-determination process: After that, the learners transfer the picture and give the search conditions based on the features they are able to identify to the system. According to the search results, the learners are able to determine the name of the butterfly being observed.

3. Self-modification process: The system further suggests a possible name list of the observed butterfly through an image-mapping technique. This gives the learners the chance to modify their previous search conditions and conclude with a different determination.

4. Self-checking process: The learner records his/her learning process in the journal, including picture of the search conditions, search results, suggestions from image mapping, and each determination he/she has made. The information recorded in the journal allows the learners to check for correctness after the activity. 


\section{METHOD}

In the section, we describe the method of our mobile butter-watching learning system, including mobile ad hoc learning environment and all subsystems supporting the self-selection, self-determination, self-modification, and self-checking processes.

\section{Mobile Ad Hoc Learning for Self-Selection Process}

To provide self-selection process, each learner in a butterfly-watching activity was able to take different butterfly pictures using his/her own color CCD camera and enter them into personal handheld device (PDA), and arbitrarily transferred the butterfly image files from the PDA to a local server (a notebook computer) by using wireless mobile ad-hoc networking (Johnson, \& Maltz, 1996; Chen, Kao, \& Sheu, 2003; Chen, Chen, \& Huang, 2002; Chen \& Ko, 2004). Figure 4 shows an example of an interface of taking a butterfly picture with the PDA. With such an interface, each learner can independently watch different kinds of butterflies and use the PDA system to arbitrarily acquire observed butterfly knowledge. This work achievement supports the self-selection process.

\section{Wireless Querying for Self-Determination Process}

There are many butterflies with similar features in the world. To provide self-determination process, we designed a wireless query system. The wireless query system consists of a content-based butterfly image-retrieval and a web-based wireless query subsystems.

First, the content-based butterfly image-retrieval subsystem automatically produces the most closely matching butterfly records from our butterfly database. The goal of the subsystem was to train the learners to have the skills to independently choose the precise answer (butterfly) from all provided estimated butterfly data files with similar features. Also, learners can indirectly acquire more knowledge from those messages about butterflies with similar features. Thus, we had to allow learners to self-organize the information as a part of the learning process; moreover, learners can organize and construct their data to form comprehensive knowledge by themselves.

In the BWL system, learners can freely choose which butterfly species is interesting. Because there is an abundance of similar butterflies, there are many butterflies with similar features in our image database. The main operation of the content-based butterfly image-retrieval subsystem is described as follows. Each learner first took pictures using the PDA's color CCD camera and transferred the pictures to the notebook computer by wireless transmission, as illustrated in Figure 5(a). After that, the content-based butterfly image-retrieval subsystem acquired the pictures, and our subsystem automatically compared the new incoming picture with all pre-stored images in our butterfly-database. The content-based butterfly image-retrieval subsystem selected the most likely butterfly-data files with similar features, and transferred the top three possible butterfly data files back to the learner's PDA, as shown in Figure 5(b). That is, a content-based image-retrieval subsystem was applied to automatically search for the most closely matching butterfly records, 
and all related information was returned to the learner. Our outdoor learning system offers real-time butterfly learning information. The system provides learners with a data-mining interface for butterfly searching, which is in a pleasurable environment, to unconsciously create a full spectrum of knowledge for a certain butterfly or related information on it. The butterfly image files were processed in our content-based butterfly image-retrieval system. Our system transferred the most closely matching butterfly-data files such as butterfly images, ecological data, and related information to the learner's mobile handheld device. Learners were able to easily study the detailed information and ecological data about the butterfly they had just observed. In addition, the similarly matching butterfly data files can be helpful for those learners who would like to learn related data.

Second, our system provides a web-based wireless query subsystem to search for possible butterfly information by providing the butterfly's features step by step, as illustrated in Figure 6 . This operation helps learners search for possible butterfly information in other way.

\section{Nature Journal for Self-Modification Process}

To support the self-modification process, we provided a teacher-modification interface in the nature journal system so that the instructor could browse all notes from the learners, as shown in Figure 7. The instructor examined the learners' nature journal, and returned the scores and comments/statements of judgment to the learners using the teacher-modification interface. The learner could review the comments/statements of judgment, sent from the instructor, in his/her own PDA. Each learner could check his/her previous observed results and could dynamically and immediately adjust and re-organize his/her knowledge of the butterfly. Learners could use the nature journal system to write notes to describe their observed results, and the butterfly-watching process and experience. Each learner's observed results might or might not have been correct, since this observed result is an independent learning result. These notes were uploaded into the instructor's notebook by wireless transmission. The instructor, who may be there in real time or who may review the students' notes later, replied with a proper comment or statement of judgment for each learner, as shown in Figure 8.

\section{Pre/Post-Testing for Self-Checking Process}

To support the self-checking process, we designed different styles of evaluation sheets on PDAs to evaluate the learning ability of learners. All data including problems, hints, and answers were automatically retrieved from the butterfly databases. Because we stored a large amount of butterfly data in the databases, we provided a user-friendly interface to do the pre/post tests. In this way, the instructor could assign questions by easily using the interface. In our system, we can add image-based questions in the evaluation sheets on PDAs. These are very interesting functions for learners when they use the system. It is very interest that this gives learners more impressions about butterflies. The interface with the assessment subject of a butterfly and selected items for learning on the instructor's notebook computer are shown in Figure 9.

In our system, we can set the time of the activities and provide tests which a learner has to 
complete. We demonstrate the process of assessment of a learner with an example. In our database, there are a number of records of butterflies in Taiwan. The instructor could select about 10 kinds of butterflies for pre/post-tests, as shown in Figure 9. Our system selects some useful knowledge to support the instructor. The butterfly information contains the family of the butterfly, the host plants, its natural habitat, the color and features of the wing, other features of the butterfly, the level of protection, and so on. Based on this function, the instructor can easily and quickly find a solution from the database. According to the conditions of each butterfly-watching activity, our system provides two different kinds of test sheets for the instructor, as shown in Figure 9. One only gives the butterfly's name, and the learner must answer all questions, including the image-based questions. Another one gives the butterfly's image, and the learner must answer with the butterfly's name, and so on. Examples of these are shown in Figure 10. Further more, the test results in real-time are displayed on the instructor's notebook and learner's PDA, as shown in Figure 11. This provides a very useful self-checking tool for learners to understand the learning status.

To adaptively examine a student's learning ability, we provide different levels of difficulty on our assessment sheet or on-line test system. For example as shown in Figure 12, when the average score is less than $40 \%$, the system provides the learner more-difficult questions. The number of choices for an answer is three. If the average score is between $40 \%$ and $60 \%$, the number of choices for an answer is four, as shown in Figure 12. Finally, if the average score is higher than $60 \%$, the number of choices for an answer is five. When a learner needs a higher support level, we provide him/her fewer choices for an answer, since there is a higher probability of selecting the correct items.

\section{RESULTS}

\section{Research Design}

In our previous study (Chen, Kao, \& Sheu, 2003), we scaffolded the learners' ability and independence by shifting the task responsibility from the expert to the learners with the learning system through a three-phase design of the experiments. Following the scaffolding model, this study focuses on learning situations in which support from the expert is withdrawn (i.e., the last phase of the experiment in the previous study). We attempted to provide evidence that the proposed system can serve as an ideal mobile aid for students to become capable, self-reliant, self-motivated, and independent learners while they are engaged in outdoor nature-exploring activities on their own. But this does not mean that learners need no scaffolds and modeling from the expert beforehand. However, we believe the process of withdrawing control by the instructor could be shorter with the help of the proposed system.

The experiment for formative evaluation was conducted in the fall semester of 2003 . One elementary school was chosen from the three participant schools of our previous study (Chen, Kao, \& Sheu, 2003). A class of 24 fifth-graders was randomly assigned to two groups, the BWL-assisted group and the guidebook-assisted group. Each group was led by a natural sciences 
teacher and a butterfly guide (i.e., the expert). The students worked in pairs as teams. Examples of the BWL-assisted group and the guidebook-assisted group are given in Figure 13.

The experiment consisted of three butterfly-watching activities for independent learning. Before the experiment, the students experienced three butterfly-watching activities led by the guide. The guide confirmed the name and key features as a species was being observed. In the meantime, teams from the BWL group practice for picture taking and information searching with the system. Teams from the guidebook group practiced picture drawing and information searches using the guidebook. After the training and modeling, students were able to explore and identify the butterflies they observe in the natural environment on their own with the help of our system or guidebook in the next three activities.

All butterfly-watching activities were held on a local butterfly-breeding farm, which is 20-minute bus ride from the school. The guide (i.e., the owner of the farm) has 17 specific species of butterflies which appear on the farm during the seasons and arranged them into six activities as target species for observation. Basically, the learners were able to encounter three new species and two old species during each activity. To avoid the practice effect, another 5 species were randomly selected so that 10 species in total appeared in the tests. The guide then picked six key features for each species as multiple-choice questions in pre-test and post-test evaluations. Pre-test and post-test evaluations were given to each team before and after the activity on the PDA. Team performance on the tests was based on the percentage of correct answers. The data collected for evaluation included test results, journals, and videotapes of each activity. Data were compared between activities and teams to evaluate the growth in the students' ability to learn independently and how they benefited from the system.

\section{Evaluation Results}

Table 1 presents the means and standard deviations of the pre-test and the post-test evaluations for each activity. Figure 14 shows the progress curves of the pre-test and post-test means of the activities for both groups.

The mean scores of the BWL group showed significant progress before and after each activity. For the first three activities, the performance level was maintained between activities. Although the performance level of the activity 3 post-test was not maintained to the activity 4 pre-test, the score was still a little bit higher than the activity 3 pre-test score. The performance of the guidebook group steadily progressed from the activity 1 pre-test to the activity 3 post-test. Although the ranges of progress in activities were not as significant as that of the BWL group, the performance level progressed even between activities. For the activity 3 and 4 pre-tests, the performance of the guidebook group showed almost the same pattern as the BWL group. A possible reason could have been that the target species for activity 4 might have been harder to identify than before.

For activity 1, only one school's pre-test data were collected, and no significant group difference was found in the post-test $(t=-0.469, p>0.05)$. For the remaining activities, ANCOVA was used to test group differences on the post-test with the pre-test as the covariate (Table 3). 
Significant group differences were found for activities 3, 4, 5, and 6. Figure 14 further presents the progress curves of the post-test mean scores for the activities of both groups.

For the first two activities conducted in phase 1, there was no difference in the post-test evaluation between the BWL and guidebook groups $(t=-0.469, p>0.05 ; F=0.042, p>0.05)$. This indicates that the students' learning might mainly have relied on the guidance of the expert instead of either the BWL procedure or guidebook assistance that was provided as enhancement in this phase of the design. For the activities in phases 2 and 3, significant differences were found between the groups for activity $3(F=5.343, p<0.05)$, activity $4(F=8.515, p<0.01)$, activity 5 ( $F=7.250, p<0.01)$, and activity $6(F=17.950, p<0.01)$ with the BWL group outperforming the guidebook group. This means that the learners substantially benefited from BWL, even though the expert support had gradually been withdrawn. The data from phase 2 provide evidence that the BWL system could be an effective discovery tool for butterfly identification. Although the learners had to search for the relevant information (with either the BWL system or guidebook) with no help from the expert in phase 3, both groups got their highest mean scores on activity 5. One possible explanation is that the learners might have better perceived their own responsibility for completing the task and focused more attention on their performance in this activity (i.e., the Hawthorne effect). The effect of phase 3 on learning was therefore increased beyond what might have been expected under normal conditions. This possible effect held for the second activity of phase 3. Activity 6 data reflected their normal performance under the condition of phase 3 . It was found that the BWL group performed even better than in the other two phases. This was because the learners had to spend more mental effort to complete the task on their own. In contrast, learners in the guidebook group almost maintained a fixed level of performance in all three phase conditions, except for activity 5. It is possible that the learners' mastery level increased as the support level decreased phase by phase, and hence the effects just balanced out.

\section{DISCUSSION AND CONCLUSION}

The method of scaffolding is especially suited for the situations where the learners' abilities have not reached the mastery level. This method can be applied to the system design as well as the instructional design. A mobile system provides many functions of supports, including maps, guides, databases, transmission, and communication for learning. A designed mobile learning activity scaffolds the learners to construct their knowledge by naturally interacting with the database, the environment, the instructors, and their peers through the system.

From our studies, we found that method of independency that can take advantages of wireless applications to make a difference in learning. When the learners have possessed certain level of ability, independent learning can be encouraged. The system can be designed to emphasize the learners' ability to complete independent learning task, such as picture taking, voice or video recording, and learning journals. BWL system should be designed to nurture student's ability of independent problem solving, knowledge retrieving, decision making, and result evaluation. The results of this study reveal that the learners found the PDA with wireless communication 
technology as a cognitive tool to be effective for constructing and organizing their personal knowledge. Consequently, this work gives the evidence that the concept of applying PDA with wireless communication technology is a "new cognitive learning tool" to access, analyze, interpret, and effectively organize their personal knowledge anytime and anywhere.

The results of this study offer important insights into how learner progress through the use of PDA (small-sized mobile computer) with wireless communication technology as cognitive tool in their knowledge construction and organization processes. This work initially reports on the development of an independent-learning-based mobile butterfly-watching learning (BWL) system for a outdoor mobile ad hoc learning. A major element of BWL system is that it allows learners to take actions which affect their own learning. Through content-based image-retrieval techniques, all beginners who go outside for butterfly watching can more quickly and easily acquire information on the butterflies they observe. Learners can immediately construct and organize their knowledge when they observe the butterflies in the outdoor learning environment. Another result of this study is the nature journal subsystem, which is an integrated learning method including an independent learning method and brand-new wireless network information technology. This nature journal helps learners to effectively complete independent learning task. This study provides the important evidences for the mobile learning for the future classroom.

\section{ACKNOWLEDGEMENTS}

The authors appreciate the helpful comments and suggestions provided by the anonymous reviewers.

\section{REFERENCES}

Chang, C. Y., Sheu, J. P., \& Chan T. K. (2003). Concept and Design of Ad Hoc and Mobile Classrooms. Journal of Computer Assisted Learning, 19:3, 336-346.

Chen, Y. S., Chen, T. S., \& Huang, C. J. (2002). SOM: Spiral-fat-tree-based on-demand multicast protocol in a wireless ad-hoc network. Computer Communications, 25:17, 1684-1695.

Chen, Y. S., Kao, T. C., \& Sheu, J. P. (2003). A mobile learning system for scaffolding bird watching learning. Journal of Computer Assisted Learning, 19:3, 347-359.

Chen, Y. S., \& Ko, Y. W. (2004). A lantern-tree-based QoS multicast protocol in a wireless mobile ad hoc network. IEICE Transactions on Communications, E87-B:3, 717-726.

Boyle, O.F. \& Peregoy, S.F. (1990) Literacy scaffolds: Strategies for first- and second-language readers and writers. Reading Teacher, 44:3, 194-200.

Bruner, J. (1983) Child's talk. Learning to Use Language. W. W. Norton, New York.

Cazden, C.B. (1988) Classroom discourse. The Language of Teaching and Learning. Heinemann, Portsmouth, NH.

Day, J.D. \& Cordon, L.A. (1993) Static and dynamic measures of ability: An experimental comparison. Journal of Educational Psychology, 85, 75-82.

Gallimore, R., Tharp, R. \& Rueda, R. (1989) The social context of cognitive functioning in the lives of mildly handicapped persons. In Cognitive Approaches in Special Education (ed. D.A. 
Sugden), 51-82. Falmer Press, Lewes.

Greenfield, P.M. (1984) A theory of the teacher in the learning activities of everyday life. In Everyday Cognition (eds. B. Rogoff \& J. Lave), 117-138. Harvard University Press, Cambridge, MA.

Guo, G.-D., Jain, A. K., Ma, W.-Y., \& Zhang, H.-J. (2001). Learning similarity measure for natural image retrieval with relevance feedback. in Proceedings. of 2001 IEEE Computer Society Conference on Computer Vision and Pattern Recognition, Hawaii, USA, 1:2, I-731- I-736.

Herber, H., \& Nelson-Herber, J. (1987). Developing independent learners. Journal of Reading, 30:7, 584-589.

Houston, K., \& Lazenbatt, A. (1996). A peer-tutoring scheme to support independent learning and group project work in mathematics. Assessment \& Evaluation in Higher Education, 21:3, 251-66.

Huang, T. S., Zhou, X. S., Nakazato, M., Wu, Y., \& Cohen, I. (2002). Learning in content-based image retrieval. in Proceedings. of The 2nd International Conference on Development and Learning (pp. 155-162). Massachusetts, USA.

Jhanwar, N., Chaudhuri, S., Seetharaman, G., \& Zavidovique, B. (2002). Content-based image retrieval using optimum peano scan. in Proceedings. of 16th International Conference on Pattern Recognition, Canada, 4:4, 130-133.

Johnson, D. B., \& Maltz, D. A. (1996). Dynamic source routing in ad hoc wireless networks. In T. Imielinski \& H. Korth (Eds.), Mobile Computing(pp. 81-153). Chapter 5.

Jonassen, D. H. (1996). Computers in the classrooms: Mindtools for critical thinking. Englewood Cliffs, NJ: Prentice Hall.

Jonassen, D. H., \& Reeves, T. (1996, 2003). Learning with technology: Using computer as cognitive tools. D. Jonassen (Ed.), Handbook for research on educational communications and technology (pp. 693-719). New York: Scholastic Press.

Kak, A., Pavlopoulo, C., Kak, A., \& Pavlopoulou, C. (2002). Content-based image retrieval from large medical databases. in Proceedings. of First International Symposium on 3D Data Processing Visualization and Transmission (pp. 138-147). Padua.

Kao, M.T. \& Lehman, J.D. (1997) Scaffolding in a computer-based constructivist environment for teaching statistics to college learners. 1997 Annual Meeting of American Educational Research Association, Chicago, IL, USA. (ERIC Document Reproduction Service No. ED 408317)

Kesten, C. (1987). Independent learning: A common essential learning. A Study Completed for the Saskatchewan Department of Education Core Curriculum Investigation Project, Saskatchewan, Canada, Regina.

Kynäslahti, H. (2003) In Search of Elements of Mobility in the Context of Education. In Mobile Learning (eds. H. Kynäslahti \& P. Seppälä), 41-48. IT Press, Helsinki.

Lafferty, G. (1996). Equity, Access and independent learning: Maximising the outcomes for mature age students. Australian Journal of Adult and Community Education, 36:2, 103-11.

Lehner, F. and Nosekabel, H. (2002). The Role of Mobile Devices in E-learning - First 
Experience with an E-learning Environment. IEEE International Workshop on Wireless and Mobile Technologies in Education, Teleborg Campus, Sweden, 103-106.

Li, X., Chen, S.-C., Shyu, M.-L., \& Furht, B. (2002). An effective content-based visual image retrieval system. in Proceedings. of $26^{\text {th }}$ Annual International of Computer Software and Applications Conference (pp. 914-919). Chicago, USA.

Maitland, L. E. (2000). Ideas in practice: Self-regulation and metacognition in the reading lab. Journal of Developmental Education, 24:2, 26-36.

Marsh, D. (1997). Computer conferencing: Taking the loneliness out of independent learning. Language Learning Journal, 15, 21-25.

Martens, R. L., Valcke, M. M. A., \& Portier, S. J. (1997). Interactive learning environments to support independent learning: The impact of discernability of embedded support devices. Computers \& Education, 28:3, 185-197.

McDonald, H., \& Ingvarson, L. (1997). Technology: A catalyst for educational change. Journal of Curriculum Studies, 29:5, 513-27.

Sariola, J. (2001). What Are the Limits of Academic Teaching? In Search of the Opportunities of Mobile Learning. Telelearning, Vancouver, Canada.

Sivan, A., Leung, R. W., Woon, C.-C., \& Kember, D. (2000). An implementation of active learning and its effect on the quality of student learning. Innovations in Education and Training International, 37:4, 381-89.

Tatar, D., Roschelle, J., Vahey, P., \& Penuel, W. R. (2003). Handhelds go to School: Lessons learned. IEEE Computer, 36:9, 30-37.

Thomas, J. J. (1993). Promoting independent learning in the middle grades: The role of instructional support practices. Elementary School Journal, 93:5, 575-592.

Tough, A. (1986). Self-directed learning: concepts and practices. In T. Husen, and T. N. Postlethwaite(Eds.), The International Encyclopedia of Education, 8. Oxford, UK, Pergamon.

Weasmer, J., \& Woods, A. (2001). Encouraging student decision making. Kappa Delta Pi Record, 38:1, 40-42.

Yildirim, Z. (2005). Hypermedia as a cognitive tool: student teachers' experiences in learning by doing. Educational Technology \& Society, 8:2, 107-117. 


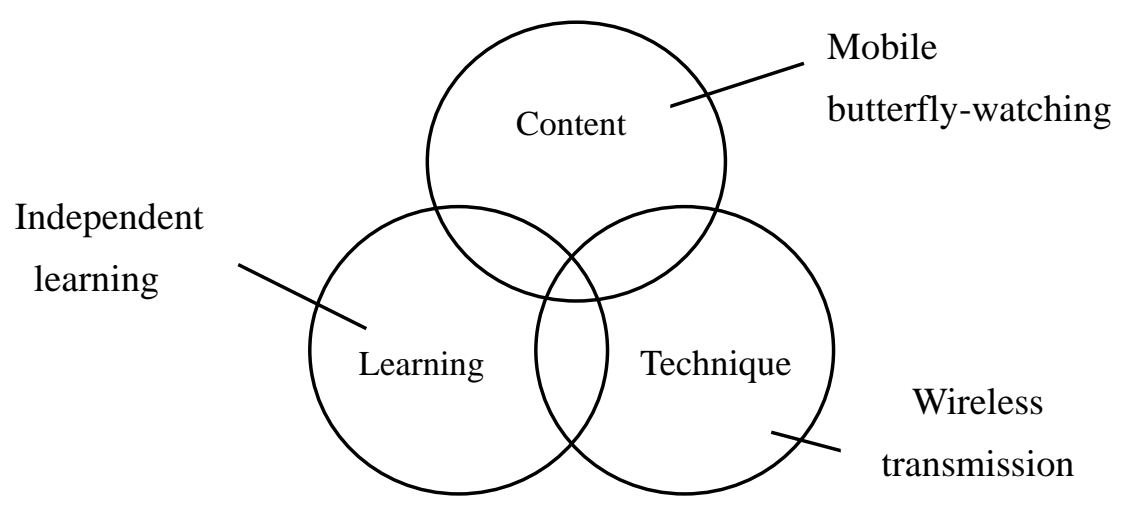

Figure 1 . The butterfly-watching learning system.

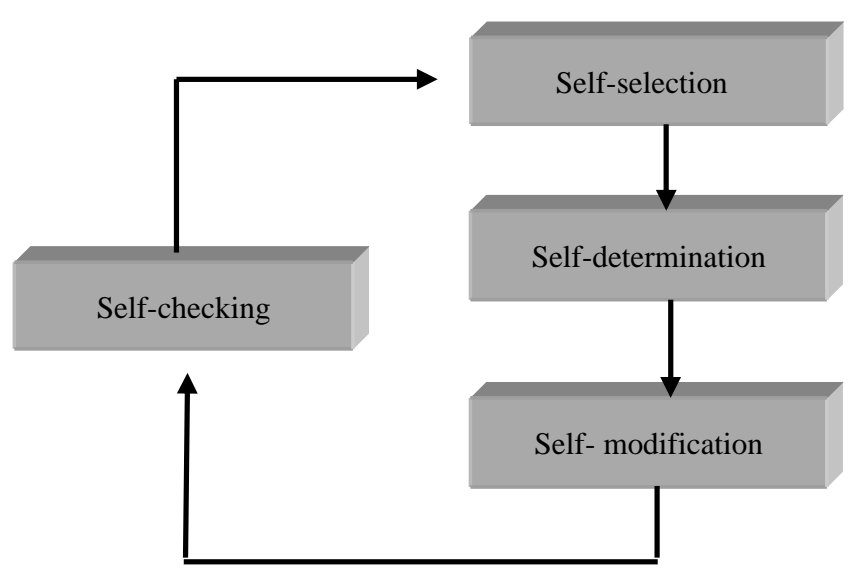

Figure 2. System flow of the independent learning method. 


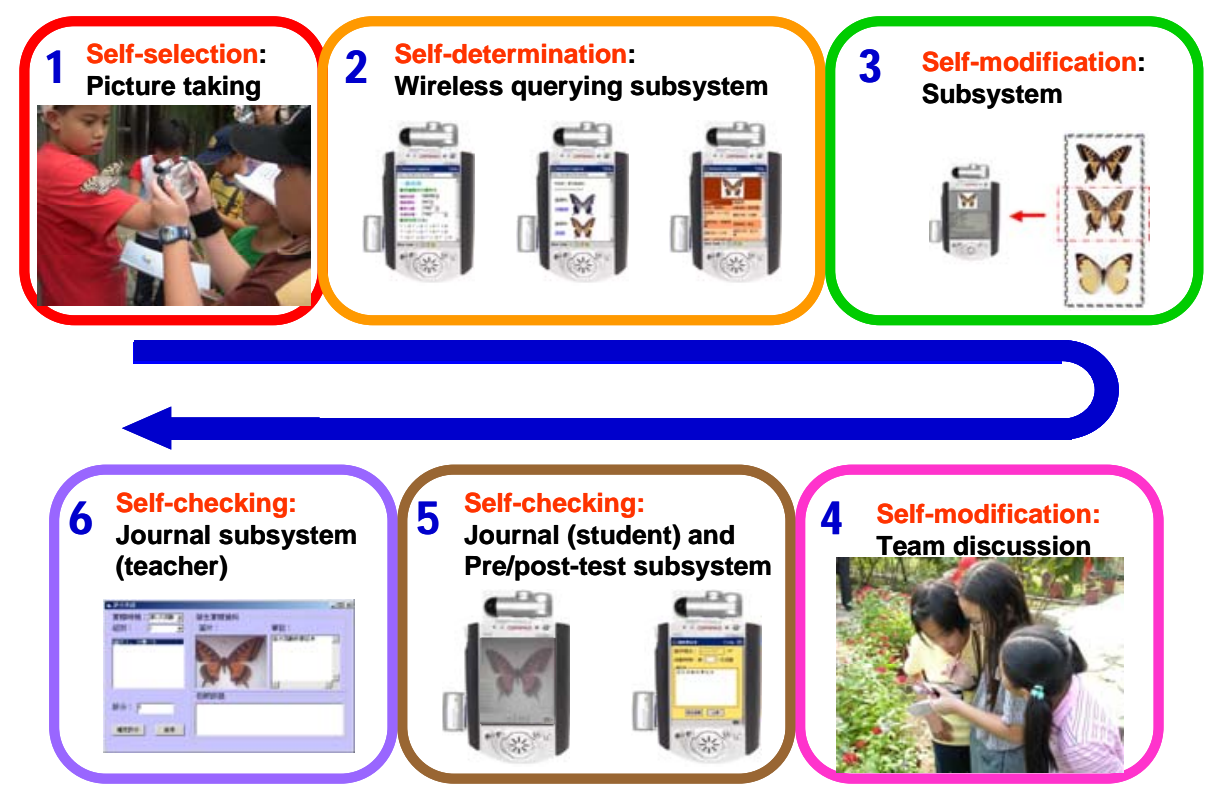

Figure 3. Learning flow chart of the BWL system.
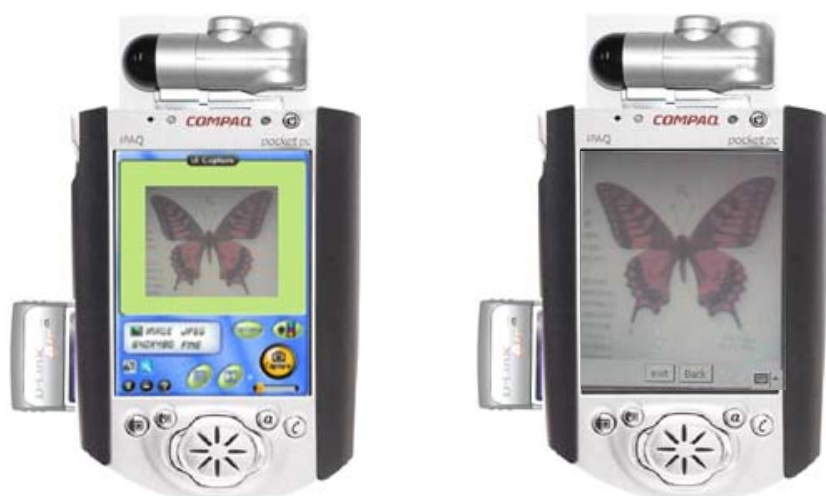

Figure 4. Interface of taking a butterfly picture. 


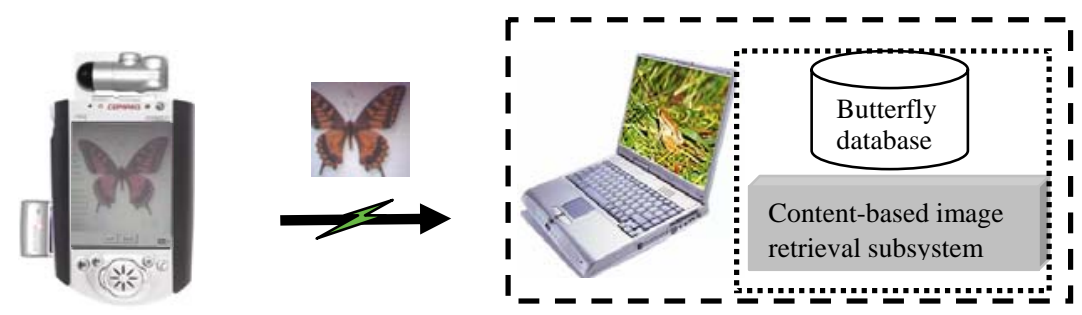

(a)
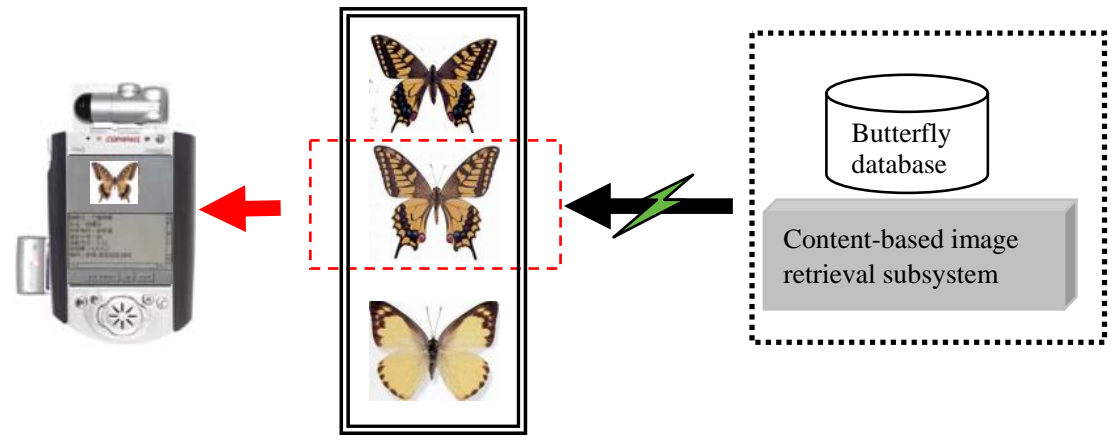

(b)

Figure 5. (a) The PDA sending a picture to the server, (b) the server returning the result to the PDA.
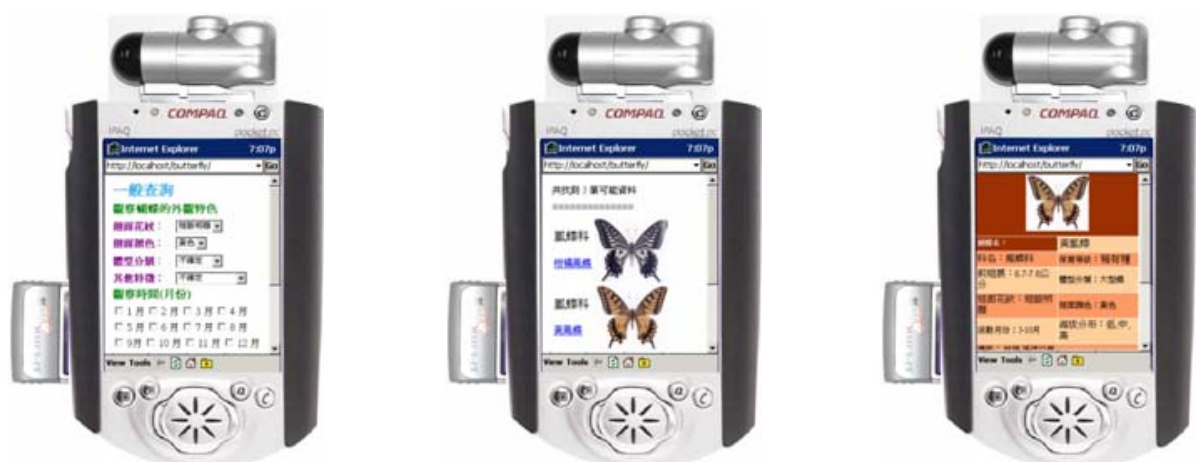

Figure 6. A web-based wireless query subsystem. 


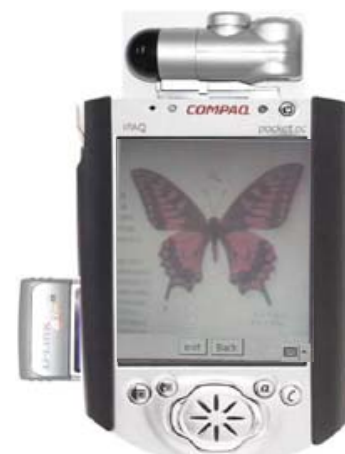

(a)

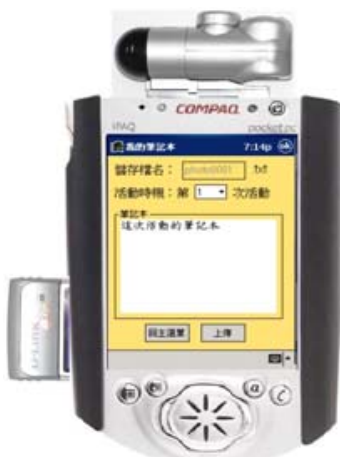

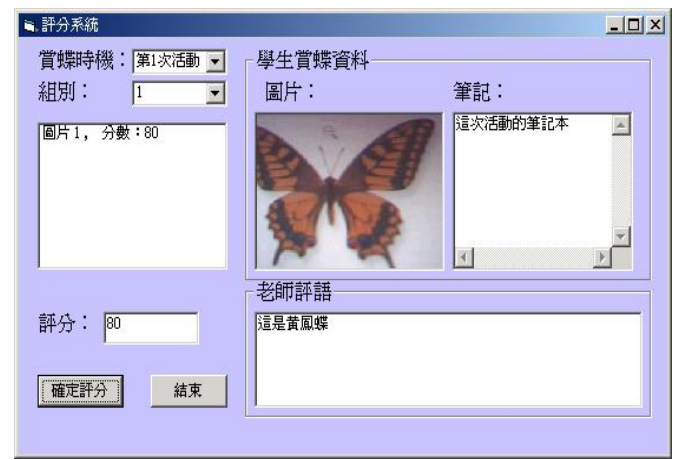

(b)

Figure 7. Interface of the nature journal subsystem (a) for the learner and (b) teacher.
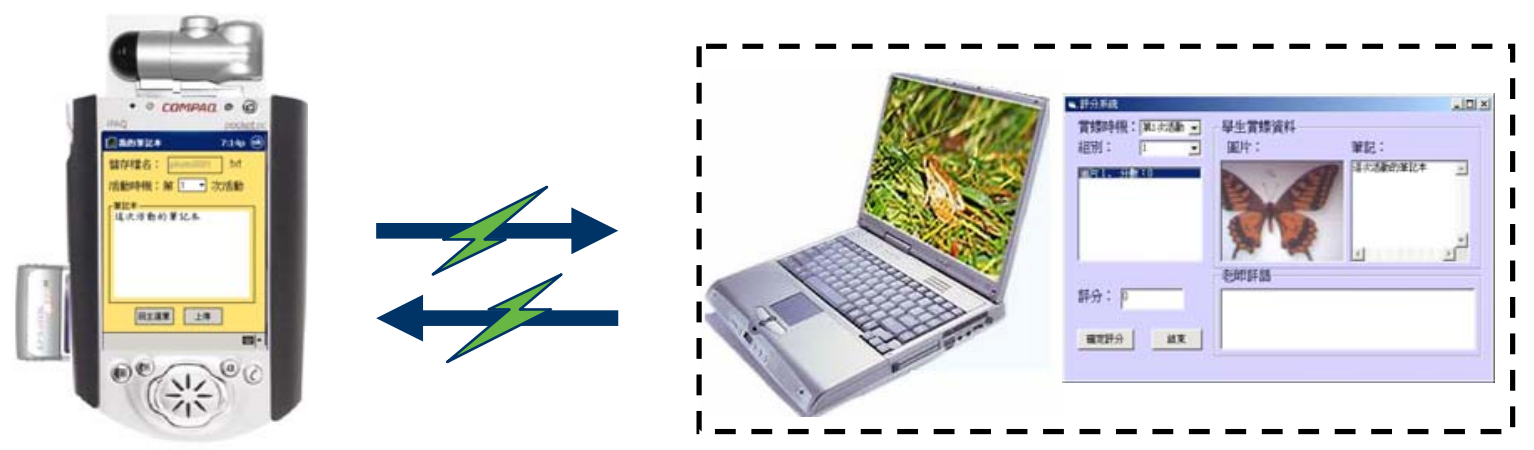

Figure 8. Uploading and downloading the nature journal. 

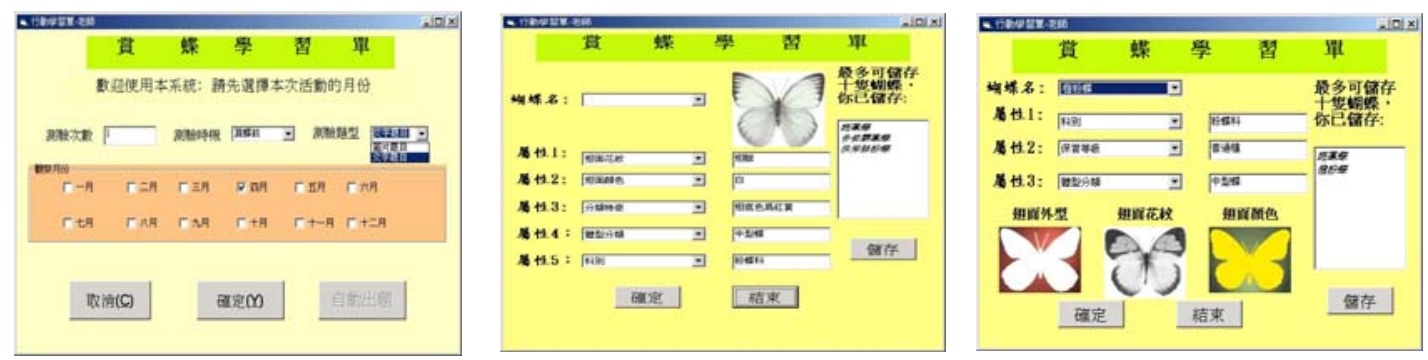

Figure 9. Assessment subject of a butterfly and selected items for learning.
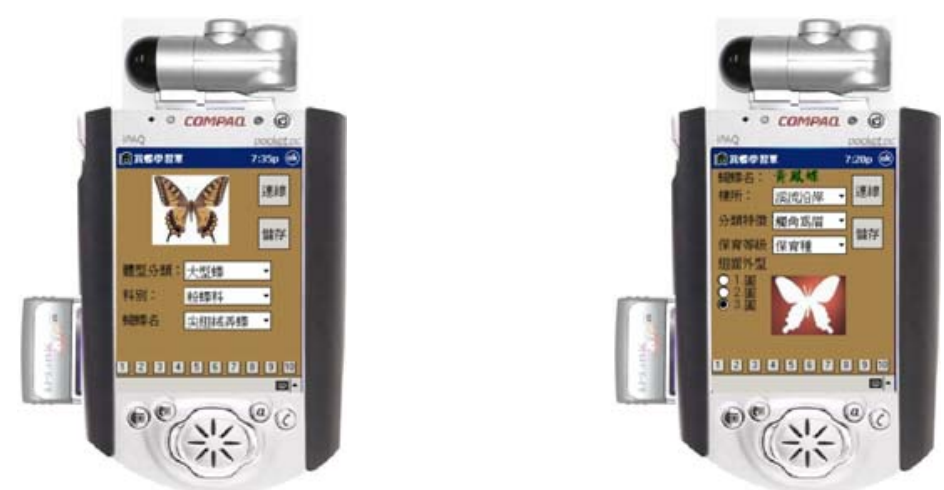

Figure 10. Two kinds of test sheets for learners. 

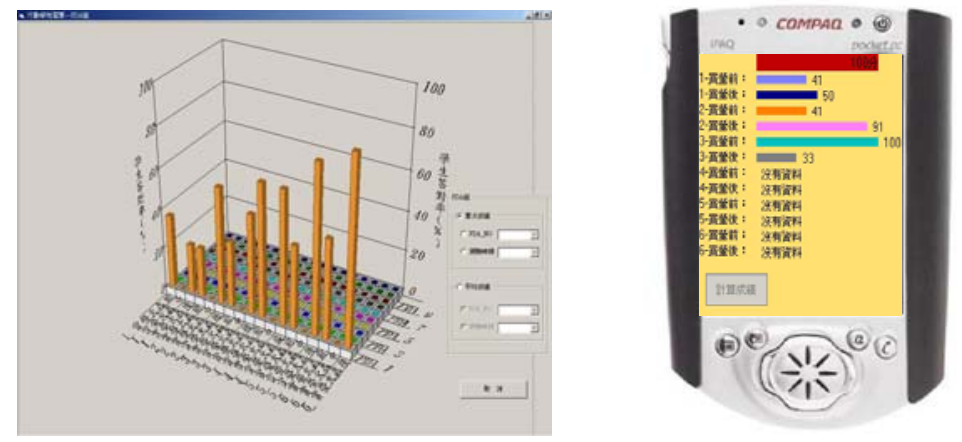

Figure 11. Evaluation results automatically produced in the notebook and PDA.
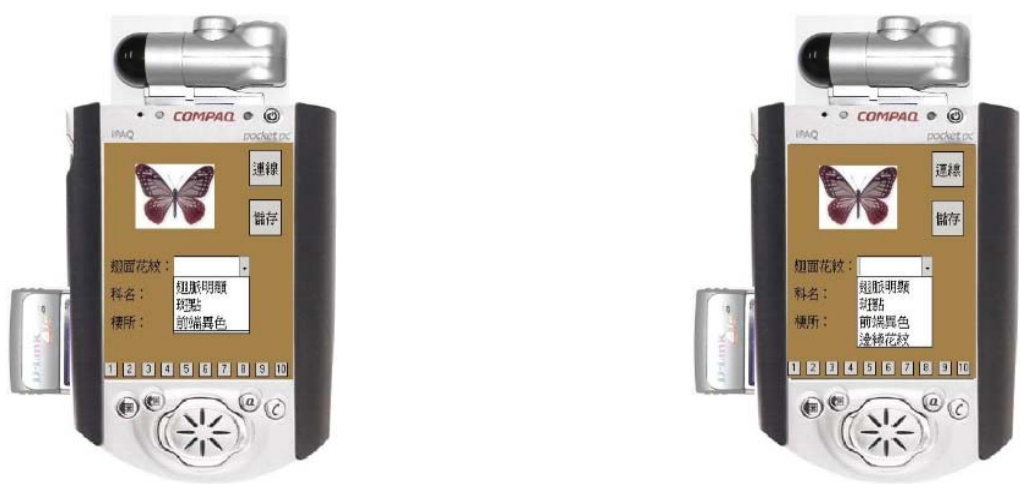

Figure 12. Example of an assessment. 


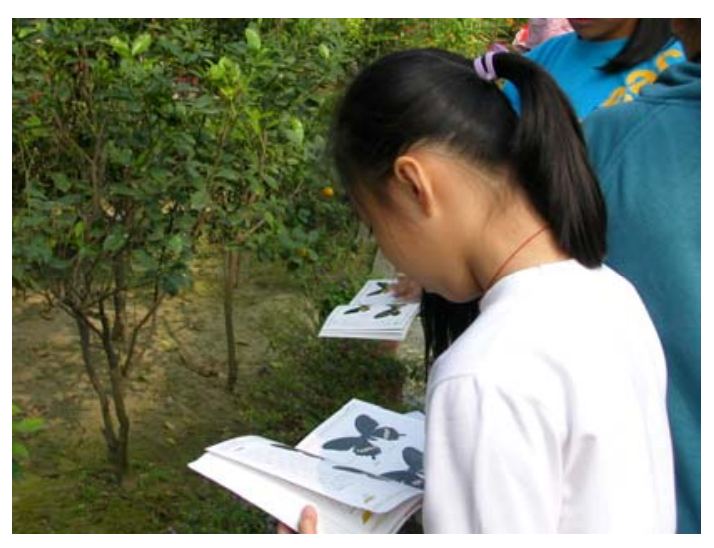

(a)

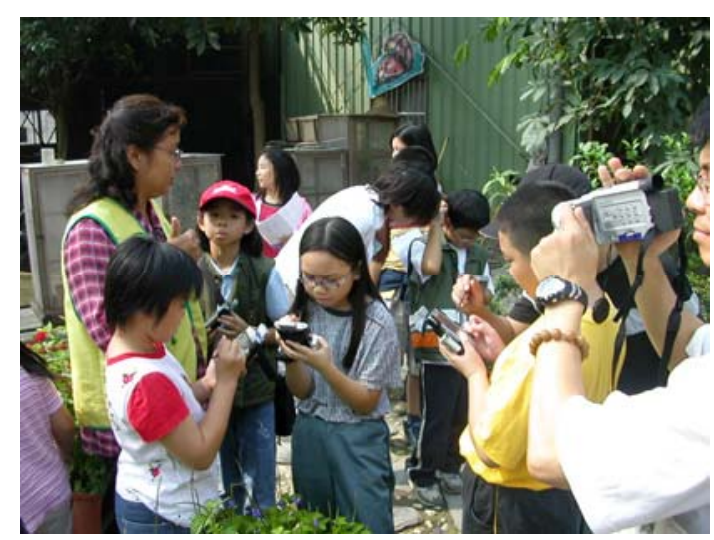

(b)

Figure 13. (a) The guidebook group and (b) the BWL group.

Table 1. Means and standard deviations of pre-test and post-test evaluations for each activity.

\begin{tabular}{llllll}
\hline & & \multicolumn{2}{c}{ BWL } & \multicolumn{2}{c}{ Guidebook } \\
\multicolumn{1}{c}{ Activity } & Evaluation & mean & s.d. & mean & s.d. \\
\hline One (1 Oct.) & Pre-test & 30.33 & 09.67 & 29.50 & 14.56 \\
& Post-test & 42.67 & 21.57 & 37.33 & 16.48 \\
Two (22 Oct.) & Pre-test & 44.17 & 11.97 & 47.33 & 12.36 \\
& Post-test & 67.17 & 14.34 & 55.33 & 14.71 \\
Three (12 Nov.) & Post-test & 87.83 & 11.74 & 58.67 & 18.61 \\
\hline Four (26 Nov.) & Pre-test & 71.33 & 09.68 & 74.33 & 18.77 \\
& Post-test & 83.00 & 05.85 & 59.67 & 14.54 \\
Five (10 Dec.) & Pre-test & 84.67 & 08.83 & 61.00 & 20.89 \\
& Post-test & 85.33 & 11.64 & 75.00 & 14.07 \\
Six (31 Dec.) & Pre-test & 80.33 & 04.68 & 66.00 & 23.22 \\
& Post-test & 84.33 & 06.74 & 64.33 & 17.82 \\
\hline
\end{tabular}




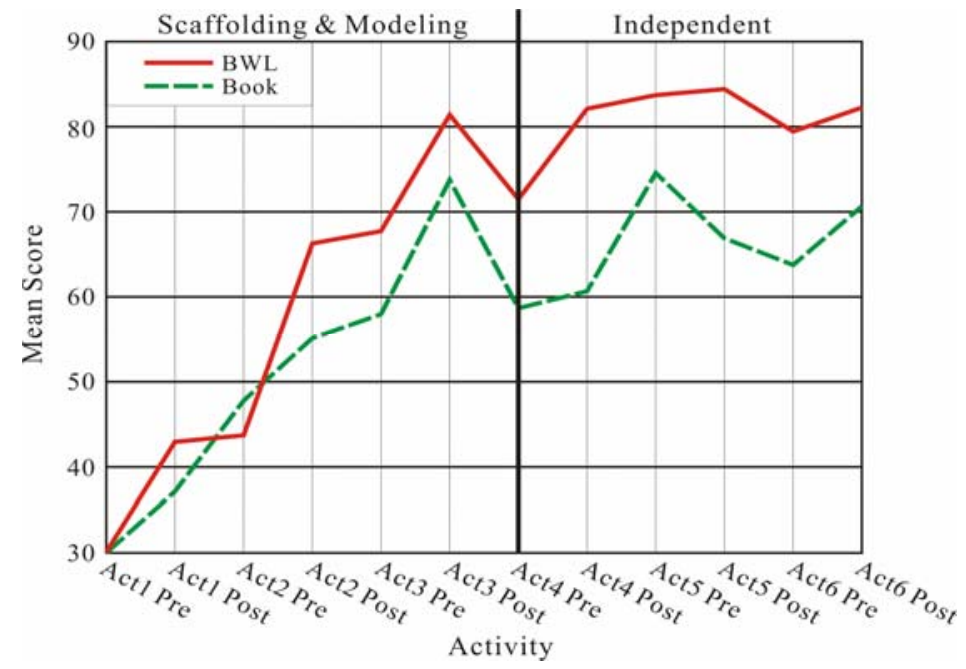

Figure 14. Progress curves of the pre-test and post-test means of the activities for both groups. 